\title{
Rate control was more cost effective than rhythm control in persistent atrial fibrillation
}

Hagens VE, Vermeulen KM, TenVergert EM, et al. Rate control is more cost-effective than rhythm control for patients with persistent atrial fibrillation - results from the RAte Control versus Electrical cardioversion (RACE) study. Eur Heart J 2004;25:1542-9.

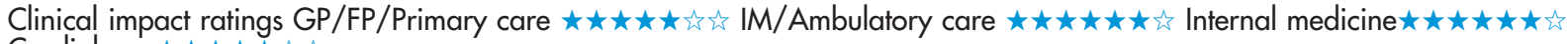

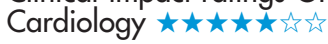

Q In patients with persistent atrial fibrillation, is rate control more cost effective than rhythm control for reducing cardiovascular morbidity and mortality?

Design: cost effectiveness analysis (from a societal perspective) of a randomised controlled trial (RAte Control versus Electrical cardioversion [RACE]).

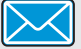

Allocation: concealed.*

Blinding: blinded (outcome assessors and monitoring committee).*

$\sum \pi$

Follow up period: mean 2.3 years.

Setting: 31 centres in the Netherlands.

(9) Patients: 522 patients who had recurrent persistent atrial fibrillation or flutter, 1-2 electrical cardioversions during the previous 2 years, and no contraindications to oral anticoagulation. Exclusion criteria: arrhythmia lasting $>1$ year, New York Heart Association class IV heart failure, current or previous treatment with amiodarone, or use of a pacemaker.

D Intervention: rate control $(n=256)$ or rhythm control $(n=266)$. Rate control included use of digitalis, a non-dihydropyridine calcium channel blocker, and a $\beta$ blocker, alone or in combination. Target resting heart rate was $<100$ beats/minute. Patients in the rhythm control group received serial electrical cardioversion and serial antiarrhythmic drugs using sotalol, 160$320 \mathrm{mg} /$ day, as the first choice, followed by class IC antiarrhythmic drugs, with amiodarone used as the last choice.

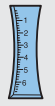

Outcomes: incremental cost savings per avoided composite endpoint (ie, death from cardiovascular causes, heart failure, thromboembolic complications, bleeding, need for pacemaker implantation, or severe effects of antiarrhythmic drugs). Costs of care (including cardioversions, medications, outpatient visits, hospital admissions, general practitioner visits, thrombosis laboratory, professional help, informal care, and travel costs) (discounted at a rate of $4 \%$ ) were estimated in 2000 European euros.

Patient follow up: $82 \%$ of patients (mean age $69 \mathrm{y}, 63 \%$ men) were included in the intention to treat cost effectiveness analysis. *See glossary.

\section{MAIN RESULTS}

The groups did not differ for the composite endpoint; however, rate control was more cost effective than rhythm control (table).

\section{CONCLUSION}

In patients with persistent atrial fibrillation, rate control was more cost effective than rhythm control for reducing cardiovascular morbidity and mortality. For correspondence: Dr I C Van Gelder, University Hospital Groningen, Groningen, The Netherlands. i.c.van.gelder@thorax.azg.nl Sources of funding: Center for Health Care Insurance; Interuniversity Cardiology Institute; 3M Pharma.
Rate control $v$ rhythm control in persistent atrial fibrillation at mean 2.3 years $^{*}$

\begin{tabular}{llll}
\hline Outcomes & $\begin{array}{l}\text { Rate } \\
\text { control }\end{array}$ & $\begin{array}{l}\text { Rhythm } \\
\text { control }\end{array}$ & Difference (95\% Cl) \\
\hline $\begin{array}{l}\text { Composite } \\
\text { endpoint }\end{array}$ & $17.5 \%$ & $21.2 \%$ & $-3.7 \%(-11.2$ to 3.9)† \\
\hline & & Cost effectiveness ratio \\
\hline $\begin{array}{l}\text { Mean cost per } \\
\text { patient }\end{array}$ & $€ 7386$ & $€ 8284$ & $€ 24944$ \\
\hline $\begin{array}{l}\text { *Composite endpoint = death from cardiovascular causes, heart failure, } \\
\text { thromboembolic complications, bleeding, need for pacemaker } \\
\text { implantation, or severe effects of antiarrhythmic drugs. Cl defined in } \\
\text { glossary. } \\
\text { tDifference not significant. }\end{array}$
\end{tabular}

Commentary

7 he RACE trial by Hagens and et al did not identify a strategydependent difference in efficacy outcomes between patients randomised to receive efforts to maintain sinus rhythm or continue with rate control. This negative result was also seen in the 4000 patient Atrial Fibrillation Follow up Investigation of Rhythm Management (AFFIRM) Study. ${ }^{1}$ In RACE, $36 \%$ of patients in the rhythm control group were in sinus rhythm by the time the study ended compared with $9 \%$ in the rate control group. Given the neutral intention to treat differences for mortality and health related quality of life $(Q O L),{ }^{2}$ the well done study by Hagens et al assessed costs in a "straight up" comparison without the need to adjust costs per QOL improvement. As seen in a similar AFFIRM analysis, ${ }^{3}$ the rhythm control strategy was more expensive. Furthermore, the costs did not differ when data were analysed by efficacy lie, who is, or is not, in sinus rhythm) as opposed to a strict intention to treat analysis. In an efficacy analysis, however, a weighted QOL approach may be needed because both the RACE $^{2}$ and AFFIRM ${ }^{1}$ trials have shown a QOL benefit associated with achieving sinus rhythm in their respective efficacy analyses.

For the older RACE and AFFIRM types of patients, no clear QOL, mortality, and now cost based reason exists to support a strategy aimed at maintaining sinus rhythm.

David Newman, MD University of Toronto Toronto, Ontario, Canada

1 Corley SD, Epstein AE, DiMarco JP, et al. Relationships between sinus rhythm, treatment, and survival in the Atrial Fibrillation Follow-Up Investigation of Rhythm Management (AFFIRM) Study. Circulation 2004; 109:1509-13.

2 Hagens VE, Ranchor AV, Van Sonderen E, et al. Effect of rate or rhythm control on quality of life in persistent atrial fibrillation. Results from the Rate Control Versus Electrical Cardioversion (RACE) Study. J Am Coll Cardiol 2004:43:241-7.

3 Marshall DA, Levy AR, Vidaillet $H$, et al. Cost-effectiveness of rhythm versus rate control in atrial fibrillation. Ann Intern Med 2004;141:653-61. 